\title{
The Semiotics of the Circus: A Note on the Italian Version of Bouissac's Analysis of Nonsense
}

\author{
Marcel Danesi
}

As a science of signs, symbols, and codes, and of their effects on patterns of individual and social cognition and behavior, semiotics allows its practitioners to cast a very wide investigative net indeed. As Eco has pointed out, the current field of semiotic practice encompasses issues related to psychology, anthropology, neuroscience, zoology, olfactory signs, tactile communication, paralinguistics, medicine, kinesics, proxemics, musical codes, formalized languages, written languages, natural languages, visual communication, systems of objects, plot structures, text theory, cultural codes, aesthetic texts, mass communication, and rhetoric (1976, 9-14). It is unlikely that De Saussure and Peirce - the founders of semiotics at the beginning of this century (1916, 1931) - could have envisaged its development into such an elastic crossdisciplinary instrument of scientific inquiry.

Perhaps the primary reason why semiotics allows one to tread so easily into so many domains of investigation is its methodological modus operandi, which - to adapt Derrida's often-used term-makes it possible to "deconstruct" any culturally-specific model of cognition or behavior into its signbased components (1972, 36-52). Virtually anything that involves codes, signs, symbols, objects, or artifacts will come within the purview of semiotic analysis.

An area that no other behavioral or cognitive science can approach in as meaningful a way as can semiotics - because it seems to defy sectorial disciplinary delimitation - is the study of humor in its culturally-institutionalized manifestations. Why is it that people laugh at, or derive gratification from, the codes of "nonsense" inherent in puns, jokes, comical skits, or clown acts at a circus? And what is the relation of this form of nonsensical semiosis to culture as a whole? It is precisely questions such as these which constitute the subject matter of Paul Bouissac's seminal study on the semiotics of the circus, which has recently been published in an Italian version under the title Circo e cultura (1986). The purpose of this review essay is to look briefly at this version, so as to extract from it any implications it might have for semiotic theory. By lifting the element of nonsense inherent in the circus scenario out of its framework of institutionalized ludicrousness, and exposing it to the clear dry light of semiotic analysis, Bouissac provides us with a 
template through which we can view, and come to understand, sense and the cultural coordinates within which it exists. As such, therefore, this brilliant book is more than a mere case study of an unusual semiotic phenomenon. It is an excursion into the perplexing universe of meaning through an analysis of its counterpart - the world of nonsense. It is, in other words, an in-depth study of homo ludens.

The translator, Andrea Semprini, has not only provided his Italian audience with a masterful translation of Bouissac's book, but he has also written a lucid and penetrating introduction (11-27), thus making Circo e cultura a kind of second edition. Semprini touches upon several matters that provide a theoretical and methodological framework within which to view Bouissac's work. The basic premise underlying Bouissac's approach is, as Semprini points out, that sense is a social gestalt. The innovative feature about Bouissac's method is that he comes to understand it through an analysis of the structure of its counterpart-nonsense. And it is the circus which provides him with a semiotic locus in which to apply the appropriate analytical techniques. Semprini goes on to point out that Bouissac's goal is to hold up the circus as a filter through which we can view and come to understand the nature of meaning. By showing how the language, acts (human and animal), participants, posters, and modes of operation of a circus constitute a code, and how this code relates to the cultural context in which it is embedded, Bouissac deconstructs sense into its elementary particles.

As it turns out, it would seem that these particles form a communication system. Meaning in any kind of human activity, and in any cultural code, is subject to the same rules that underlie the phenomenon of human speech. As Whorf argued a few decades ago, everyday acts of cognition and characteristic social behaviors do not exist independently from the labels and categories used to codify them linguistically (1956). The rules of language are the rules of "sensicality." As Bouissac argues eloquently and persuasively, it is when these rules are manipulated to create nonsensical behaviors that laughter is evoked. Humor is, in other words, a concomitant of institutionalized displays of "nonsensicality." Since it would be well beyond the scope of the present discussion to deal with all the components of the circus code, I will look briefly at Bouissac's treatment of clown acts as a case-in-point of his main hypothesis.

Like all other aspects of a circus performance, clown acts do not vary significantly from one performance to another, and can thus be described and analyzed with a high degree of precision. In order to be successful, clown acts must be synchronized to the culturally-determined expectations of an audience. For this reason, clowns will tailor their acts in accordance with the country in which they carry out their routines. Audience expectations of nonsensicality are, of course, shaped by infringements upon culturally-specific codes of sensicality. And this means that clown acts are highly-structured ones: "un numero di clowns non è semplicemente un cumulo di gags senza 
relazione tra loro, ma una performance altamente strutturata" (141). In this structured scenario, laughter constitutes the "control mechanism" for ascertaining whether or not the act has obtained its desired outcome.

The analysis of clown humor leads to the conclusion that a clown act is, in effect, a communication act. It is based on verbal features (sounds, facial cxpressions, gestures, stock phrases, etc.) which have been gleaned from the cultural environment and then transformed into nonsensical laughter-evoking routines. And like a specch act, it unfolds in the form of "un numero di media percepibili come conduttori di clementi discreti" (142). "These discrete units give a clown "la possibilità di mettere in opposizione per qualche aspetto questi elementi e di controllarli in qualche modo" (142). Humor is seen, therefore, to constitute a kind of metasemiotic opcration.

To illustrate his hypothesis, Bouissac describes the clown act of the famous ninetecnth-century clown Joseph Grimaldi. Grimaldi was particularly renowned for his "jokes of construction" in which he used feminine objects and symbols (e.g. garments and fireplace objects) to construct situations in which he juxtaposed his role as a warrior against the symbology of such gender-coded items. His accessories are described as follows:

Il cappello: un manicotto da donna, con un orologio da tasca appeso ad un lato c una spazzola da tavola che sporge dal bordo; gli alamari e le decorazioni sono riprodotte con pezzi di corda; gli stivali: un paio di secchi da carbone (accomodati con speroni); la spada: un attizzatoio. (149)

These juxtapositions create a matrix of nonsensical oppositions: "Gli accessori selezionati da Grimaldi erano simili per forma e materiale all'uniforme di un vero ussaro, ma diversissimi in relazione al sistema culturale esistente" (149). In other words, clown acts are shaped by a kind of "grammar of nonsense" which elicits a humorous response because it pits culturally-defined signs and symbols against each other in a nonsensical matrix of oppositions. This model of humor is, of coursc, in stark opposition to widely-held psychological theories that view it as resulting from the unexpectedness and incongruity of a situation. But this does not explain, as Bouissac maintains, the fact that clown acts are funny because they are highly predictable and congruous routines. Bouissac's "communication" model is clearly more compatible with this fact: "La dicotomia fondamentale dei numeri dei clowns... mostra come lo stato iniziale costruito dai clowns simboleggi in modo ridondante ... l'opposizione tra norme culturali e "anormalità' culturali" (144).

Theories of humor and laughter range all the way from psychoanalytic ones which view humor as a release of internal aggression (Bergler, 1956), to those which stress the element of surprise and incongruity (Morgan and King, 1966, 265). However, the main thrust of the research has shown that humor is tied to social perceptions and processes. A number of studies have, in fact, shown that even the earliest smiles of very young infants reflect a basic communication need involved in the expression of pleasure (Mindess, 
1971; Goldman and McGhee, 1972). Social situations enlisting nonsensical routines (e.g. contrived facial expressions, unusual gestures or sounds, etc.) all elicit smiles and laughter if tied to a specific context. This sense/nonsense dichotomy would seem to have a basis in neurology. In an interesting experiment, Gardner, Ling, Flamm, and Silverman showed that aphasics (patients with impairments to the left hemisphere of the brain) do not lose their ability to laugh and enjoy normal humorous situations, whereas those with damage to the right hemisphere often miss the point of a nonsensical routine (1975). This would seem to suggest that humor has a neurological locus in the right hemisphere (the intact one in aphasics), thus tying it to those psychological faculties involved in producing imaginative thought. The right hemisphere is the part of the brain that is responsible for making "illogical" associations possible. It would appear, therefore, that Bouissac's model has coordinates in the domain of cognitive science research. In his model, the code of a clown act is not a haphazard, random, or incongruous concoction of movements and words. It is a highly-structured routine that is tied to right-hemisphere functions that allow us to contextualize nonsensical juxtapositions of sociallycoded symbols. Homo ludens is thus seen to be the neurological alter ego of homo loquens.

It is also interesting to note that Bouissac's semiotic analysis of nonsense is remarkably similar to Arthur Koestler's views on humor expressed in his brilliant study of the creative imagination (1964). According to Koestler, there is a pattern to humor which consists in a systematic reversal of logic brought about by "a momentary fusion between two habitually incompatible matrices" (94). Koestler goes on to explain that the term "matrix" refers to a code. Humor is a creative (right-hemisphere) phenomenon involving a complex pattern of oppositions which, somehow, elicit a sharply defined reaction (a smile, a laugh, etc.) akin to that of a physiological reflex. Thus it is that the "pattern underlying all varieties of humor is 'bisociative' - perceiving a situation or event in two habitually incompatible associative contexts" (95).

To conclude, it is fitting to have available an Italian translation of Bouissac's insightful treatise on the semiotic nature of nonsense, given the fact that Italy may have been the first to give the world the prototype of the clown routine in the antics of the Commedia dell'Arte. The code of the circus allows us to understand how it is that we make sense. As Bouissac concludes, meaning in human actions is a consequence of the signs which "formano il nostro ambiente socio-culturale" (198). Within its own grammatical code, the circus does indeed make sense, but only in relation to the larger cultural context. In other words, the meaning of any human action, whether it be sensical (i.e. socially-coded) or nonsensical (coded by juxtaposed sign systems such as that of the circus), is determined by the rules of the code itself. Thus it is that a code can either make sense or nonsense in semiotically-identical ways. When it makes sense, it produces behaviors that are characteristic of homo loquens; when it makes nonsense, it produces behaviors that are indicative 
of homo ludens. Both are complementary facets of the personality of homo sapiens.

\section{University of Toromo}

\section{Works Cited}

Bergler, Edmund. Laughter and the Sense of Ilumor. New York: International Medical Book Co., 1956.

Bouissac, Paul. Circo e cultura. Palermo: Sellerio Editore, 1986. (English version: Circus and Culture: A Semiotic Approach. Bloomington: Indiana University Press, 1976.)

De Saussure, Ferdinand. Cours de linguistique génćrale. Paris: Payot, 1916.

Derrida, Jacques. "Structure, Sign, and Play in the Discourse of the Human Sciences." In The Siructuralist Controversy. Eds. E. Donato and R. Mackscy. Baltimorc: John Hopkins University Press, 1972.

Eco, Umberto. A Theory of Semiotics. Bloomington: Indiana University Press, 1976.

Goldman, G. D. and P. E. Mcghec (cds.). The Psychology of Humor. New York: Academic Press, 1972.

Gardner, H., P. K. LING, L. Flamm, and J. Silverman. "Comprehension and Appreciation of Humor in Brain-Damaged Patients." Brain 98 (1975): 399-412.

Koestler, Arthur. The Acl of Creation. Suffolk: Pan Books, 1964.

Mindess, Harvey. Laughter and Liberation. Los Angeles: Nash Publications, 1971.

Morgan, C. T. and R. A. King. Introduction to Psychology. New York: McGraw Hill, 1966.

Peirce, Charles Sanders. Collected Papers, 8 vols. Eds. C. Hartshorne and P. Weiss. Cambridge, Mass.: Harvard University Press, 193 I.

Whorf, Benjamin Lee. Language, Thought, and Reality. Ed. J. B. Carroll. Cambridge, Mass.: MIT Press, 1956. 